\title{
THE KINETICS OF CONE VISUAL PIGMENTS IN MAN
}

\author{
Mathew Alpern, Frode Maaseidvaag and Norio Ohba \\ Department of Ophthalmology, University of Michigan, Ann Arbor, Michigan 48104, U.S.A.
}

(Received 20 August 1970)

THE KINETICS of the normal human red and green cone pigment chlorolabe and erythrolabe have been extensively studied by Rushton in three important papers (RUSHTON, 1958, 1963, 1965). With his retinal densitometer he measured the fraction $p$ of foveal pigment left unbleached by a $10 \mathrm{sec}$ flash of intensity $I_{1}$. This was done by suddenly substituting for $I_{1}$ at the end of the $10 \mathrm{sec}$ a smaller value $I_{2}$ chosen so that further photolysis was exactly balanced by regeneration and $p$ was seen to remain steady indefinitely. This gave plenty of time for a good measurement of $(1-p)$, the fraction bleached by the $10 \mathrm{sec}$ exposure to $I_{1}$.

Assuming that in vivo (as in vitro) the photolysis rate is proportional to the quantum catch I.p, and that during the $10 \mathrm{sec}$ exposure regeneration is negligible (as was confirmed experimentally),

$$
-d p / d t=I p / Q_{e}
$$

or, when bleaching is applied to the fully dark eye where $p=1$

$$
-\ln p=10 I_{1} / Q_{e}
$$

The experiment was done, $p$ plotted against $\left(10 I_{1}\right)$, and the results found to coincide well with the theoretical curve (2) when this was suitably displaced along the $\log \left(10 I_{1}\right)$ axis. The shift gives the value of $Q_{e}$ (the energy needed to bleach to $1 / e$ of the initial value). $Q_{e}^{-1}$ is known as the photosensitivity.

Knowing $Q_{e}$, Equation (1) gives the photolysis rate if $I$ and $p$ are also known. These Rushton knew in the equilibrium state under $I_{2}$ at every $p$ level; hence at every level he could calculate the photolysis rate and consequently the rate of regeneration which exactly neutralized it. The regeneration rate in these special conditions was found to be proportional to $(1-p)$, the fraction of pigment bleached.

Now the regeneration rate in the dark at any $p$ level is easily measured by drawing a tangent to the curve plotting the time course of dark recovery following a full bleach. The rate so measured was found also to be proportional to $(1-p)$, and the constant of proportion was the same in the two cases. It thus appeared that regeneration restored the bleached rhodopsin at a rate simply proportional to the amount still to be restored and independent of any bleaching that might be superimposed upon that process. The full kinetic equation which represents this superposition is thus

$$
-d p / d t=\left(I p / Q_{\mathrm{e}}\right)-(1-p) / t_{o}
$$

where $t_{o}$ is the time constant of regeneration in the dark.

To avoid the ambiguity of the expression "bleaching rate", - $d p / d t$ is called "net bleaching rate" (or net regeneration rate when of opposite sign). It is the difference (Equation 3) of $I p / Q_{e}$ which is the "photolysis rate", and $(1-p) / t_{0}$ the "recombination rate". 
The kinetic equation was derived from measurements on a single cone pigment found in protanopes' and deuteranopes' fovea, but RUSHTON (1958) and RUSHTON and HENRY (1968) found that because the two red green cone pigments regenerated with very nearly the same time constants it was also valid (though with a slightly larger $Q_{e}$ ) for the mixed pigment of the normal fovea, provided "white" light was used for bleaching. Hence the results of measurements of the two red green pigments of the normal fovea could be treated as though only a single pigment was involved.

Although Equation (3) successfully accounts for a variety of facts regarding cone pigments kinetics there are considerations which suggest it may be an oversimplification.

It is known that the pigments are synthesized by a combination of the free opsin $(1-p)$ and 11-cis retinal $(y)$. This reaction

$$
\begin{gathered}
\text { free opsin }+11-c i s \text { retinal } \rightarrow \text { cone pigments } \\
(1-p) \quad y
\end{gathered}
$$

should proceed at a rate proportional to the products of the components of the reaction

$$
d p / d t=K(1-p) y,
$$

in which $K$ is the rate constant of the reaction. To account for the fact (Rushron, 1964) that regeneration following long full bleaches proceeds about twice as slow as regeneration after short full bleaches, RUSHTON and HENRY (1968) proposed that in the former the store of 11-cis retinal $(y)$ had been exhausted but in the latter it was not. Thus the value of $t_{\theta}$ in Equation (3) $(1 / K y)$ is not a constant in this view but varies with the level of $11-c i s$ in the store. It leads to the expectation that $t_{0}$ will be shorter for the recovery from prolonged weak bleaches than from prolonged strong ones.

A second way Equation (3) may conceivably break down is in the presence of early colored photoproducts of the bleaching which disappear before regeneration. If they absorb the densitometer measuring light they might cause the value of the rate of photolysis at equilibrium estimated from the initial rate to differ from the actual value.

In this paper we have tested how far Equation (3) is accurate in describing cone pigments kinetics in a normal retina by measuring the rate of initial photolysis to prolonged exposures at a variety of different intensities and observing regeneration after these bleaching lights are extinguished. We find it entirely accurate.

\section{Appararus}

\section{MATERIALS AND METHOD}

Tho appantus is a modification of the Floride model of the rotinal dearitometer deacribed by Hoon and

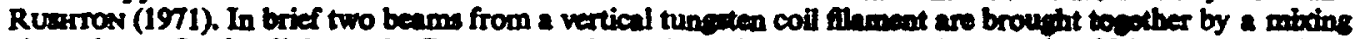

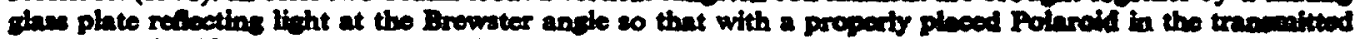

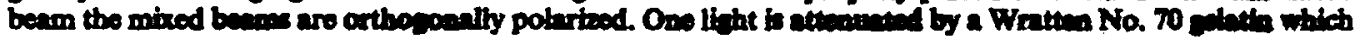

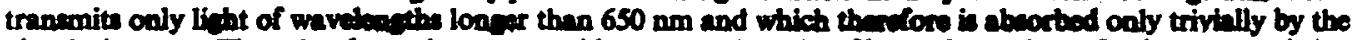

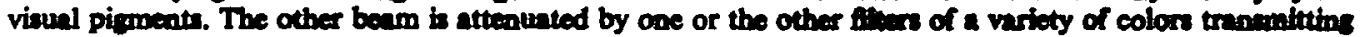

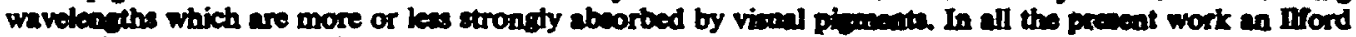
625 (Bricht Spectrum Yellow Green) was used in this beam. The two benm are fichered by a common rotatins Polaroid which in our experiments produced a sine weve oncillation at the mite of 17.1 Hz. This light is reflected into the eys by Minxwelling view of a fint surfece cohthalmosope mirnor immediately in front of the widely ditated pupil. The lipht refected from the fundus (by paining the ophthlmoscope mirror)

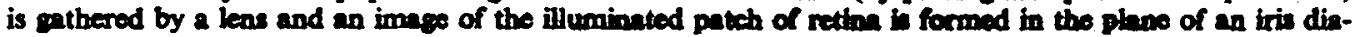
phrem immadintely in front of an EMI 9558 B photomukipliex tube. Tho output of the tabe in proportional

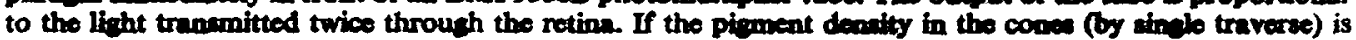
less then 0.1 then the photocell simal which is linear with pioment absorption will be proportional to the amount of cons pioment present. We assume this to be the case. 
The sinewave output of the photomultiplier is detected by a PAR (JB4) Lock-in amplifier tuned to the frequency of the rotating polaroid and nulled by a wedge in the beam which passes through the Wratten No. 70 filter (i.e. "the red wedge"). A bleaching light of any desired color (in these experiments always white) is also refiected into the eye. A carefully positioned episcotister in a light trapped housing alternately exposes the bleaching light or the photomultiplier tube in such a way that no light from the bleaching field ever gets into the photomultiplier tube. In all these experiments we exposed the bleaching light at a frequency of $250 \mathrm{~Hz}$; it appeared continuous.

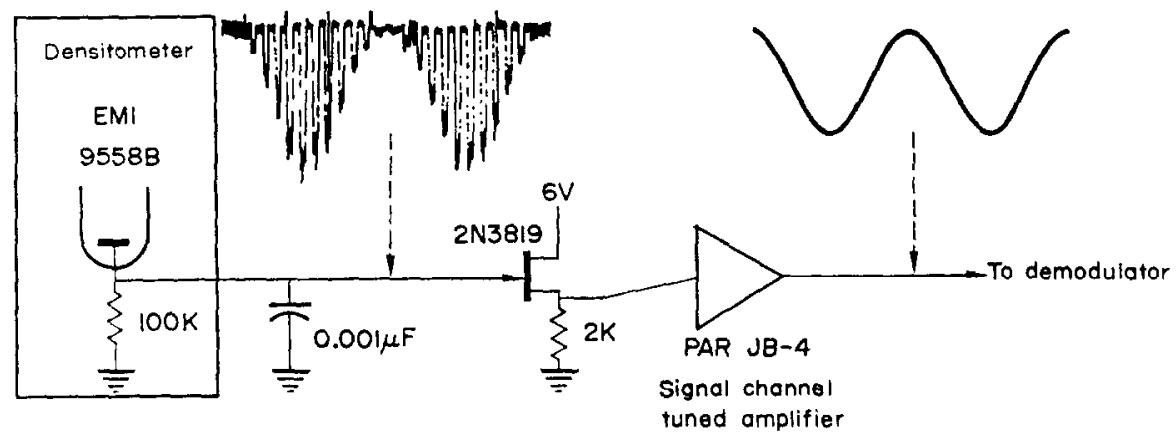

FIG. 1. The electronic circuit which provides the interface between the densitometer photomultiplier tube and the tuned amplifier. This is the only modification made of the retinal densitometer described by HoOD and RusHTON (1971).

The ratio between the sampling $(250 \mathrm{~Hz})$ and the measuring light $(17 \cdot 1 \mathrm{~Hz})$ frequencies is large. The tuned amplifier therefore will reproduce the original signal output from the photomultiplier tube as shown in Fig. 1. The impedance interface between the EMI 9558B and the PAR Lock-in amplifier is accomplished using a simple source follower. The $0.001 \mu \mathrm{F}$ capacitor in parallel with the 100K EMI 9558B lead resistor filters out most of the high frequency noise present in the photomultiplier tube.

\section{Procedure}

The subject was accurately aligned in the densitometer by adjusting the bite bar and the ophthalmoscope mirror. He then removed his head from this position and dark adapted for $10 \mathrm{~min}$, a duration long enough for all measurable foveal pigments to regenerate completely. After the subject was repositioned in the instrument in full dark adaptation the red wedge was adjusted to balance the photomultiplier output produced by the fundus reflection of the red and green measuring lights. This measurement was repeated five times. The red beam usually required an additional $2 \cdot 0$, the green an additional 0.5 , neutral to obtain a proper balance in the useful range of the wedge. No measurable amount of pigment was bleached by the measuring light under these conditions. Once the dark adapted values had been obtained the bleaching light was exposed at a predetermined intensity. Measurements were made at successive moments after the onset of the bleaching, initially as rapidly as possible, then more slowly until equilibrium was reached. The bleaching light was then extinguished and the regeneration followed until achicving the full dark adapted value once more. Next the pigments were fully bleached and the wedge settings measured first under this condition and then during subsequent regeneration in the dark.

Occasionally a second repetition of the partial bleach-regeneration sequence was obtained at the same sitting. Bleaching at only one intensity was ever undertaken in one given sitting and usually only a single sitting was ever tried on any given day. The subject for all these experiments was N. OHBA, who used his left eye which is about 3 diopters myopic.

\section{THEORY}

Figure $2 \mathrm{a}$ shows the amount of pigment remaining as a function of time $(t)$ after the onset of a light which bleaches about 46 per cent of the cone pigments at equilibrium. At the start $(t=0)$ the eye was fully dark adapted so that all pigment was regenerated and the rate of recombination may be assumed to be zero. According to Equation (1) the initial photolysis rate is

$$
d p / d t=-I / Q_{e}
$$




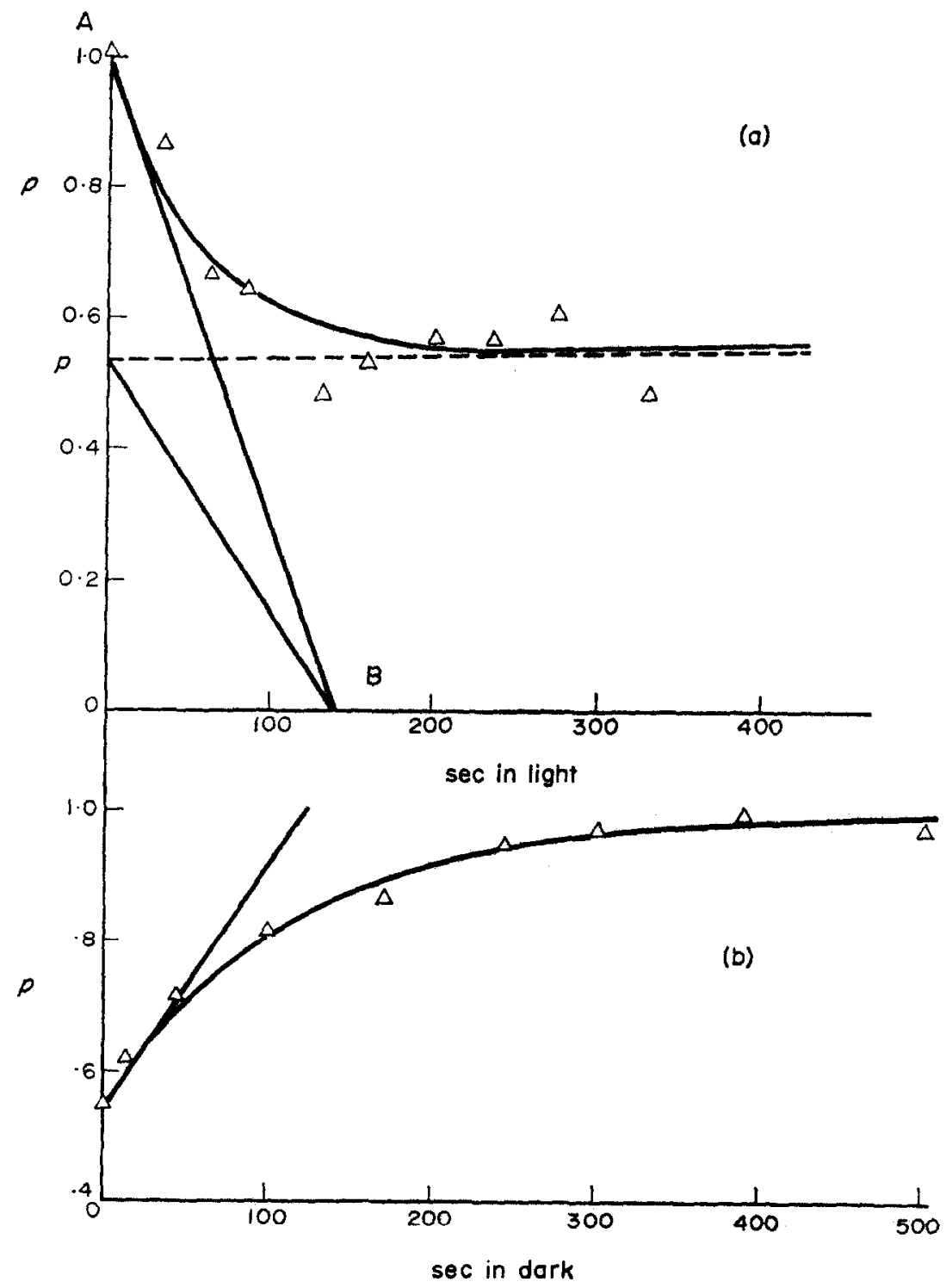

Fro. 2. Principle of the andysis (a) bleaching (b) meaneration in the dark. The initial photolysis rate is eiven by the slope of the line $A B$ and the photolyni rate at any other moment is the product of this and the level of unbleschod simpat. Heeco at equilibrium bovel $P$, the photolysis rate is given by the slope of the line $P B$. The recombination rate at oquitibrium is given by the tangent to the curve at the moment the bleachins light was extinguishod. In the actual experiment run (b) followed immediately after (a), though for convenience in plotting the time scale has been reset to zero at the moment the bleaching light was extinguished.

and this is the slope of the line $A B$. In general at any moment $t$ the rate of photolysis will be the amount of unbleached pigment $p$ times this value. Specifically, the value of the estimated rate of photolysis at equilibrium is the slope of the line $P B$. It can be computed by multiplying the equilibrium value of $P(0.545)$ by the slope $\left(-I / Q_{e}=1 / O B=1 / 142 \mathrm{sec}^{-1}\right)$. The product is $0.545 / 142=0.00384$ or $0.384 \mathrm{per}$ cent $/ \mathrm{sec}$. This, of course, rests on the 
assumption that there are no early colored photoproducts which disappear prior to regeneration. This is an assumption we wish to test. We do so in the following way:

At equilibrium the rate of photolysis must be equal and opposite to the rate of recombination, by definition. We measure the rate of recombination at equilibrium and compare this value to that estimated from the initial rate of photolysis as illustrated in Fig. $2 \mathrm{a}$. The method is shown in Fig. $2 \mathrm{~b}$ which is reset at $t=0$, though in the actual experimental run it was a continuation of the same experiment illustrated in Fig. $2 a$ and followed it immediately. At $t=0$ the bleaching light was cxtinguished and the pigment regenerated in the dark along the curve as shown. The initial rate of recombination in the dark (which is also the final rate of recombination at equilibrium in the light and by definition therefore exactly equal and opposite to the final rate of photolysis at equilibrium in the light) is given by the tangent to the regeneration curve at $t=0$ in the dark. The rate may be computed by dividing the value $(1-p)$ at equilibrium $(0.455)$ by the value of $t$ at which the tangent to the curve at $t=0$ strikes the line $p=1 \cdot 0$. Since the regeneration follows an exponential curve (Rushton, 1958) this value is $t_{0}$ the time constant of regeneration. In Fig. $2 b, t_{o}=122 \mathrm{sec}$ so that the rate of regeneration at equilibrum is $0.455 / 122=0.00373$ or $0.373 \mathrm{per}$ cent $/ \mathrm{sec}$, a value very nearly the same as that estimated for the rate of photolysis at equilibrium from the initial rate in Fig. 2a.

\section{SOURCES OF ERRORS}

With very bright bleaches the estimate of the rate of photolysis at equilibrium is at best only approximate since a very small error in measuring the point $B$ in Fig. 2a leads to a large error in the estimation. An analogous difficulty occurs in the calculation of the rate of recombination after very small bleaches in which the value of the time constant of regeneration $t_{0}$ is difficult to estimate exactly. These estimations were made in the following way: It has been shown (Rushron, 1958), and we confirm, that these bleaching and regeneration data are adequately described by simple exponential curves. In the case of each set of bleaching measurements we first identified the ordinate asymptote for infinite time and computed the differences between the ordinate for the measurement at time $t$ and this asympotote value. The log of this difference was plotted as a function of (linear) time and the best fitting straight line was drawn by eye through the points.

A second source of errors related to the finite size of the bleaching beam aperture stop. The diameter of its image in the plane of the subject's pupil was $2.5 \mathrm{~mm}$. With the pupil fully dilated to $7.5 \mathrm{~mm}$, the apparatus precisely aligned, and the fixation perfectly steady, this was well inside the temporal half of the pupil and served as a proper aperture stop for the bleaching field. However, the safety factor is only $1.25 \mathrm{~mm}$, a rather small limit.

Occasionally (usually near the end of a prolonged experiment) either because the mydriasis gradually waned, or fixation wandered, or the head shifted slightly (or perhaps some combination of these), one edge of this image was occluded by the temporal margin of the iris. This, of course, reduced the intensity of the bleaching light reaching the retina and resulted in a variable (rather than a constant) amount of bleaching intensity if - as a result, say, of eye movements during fixation-the iris sometimes occluded, sometimes did not. Sometimes the errors so introduced could be readily identified by the loss of mydriasis at the end of the experiment, but this was not always the case.

\section{RESULTS}

A. Early color bleach products. The results in Fig. 2 show that in that case the estimated equilibrium rate of photolysis computed from the initial rate of photolysis was in fairly 


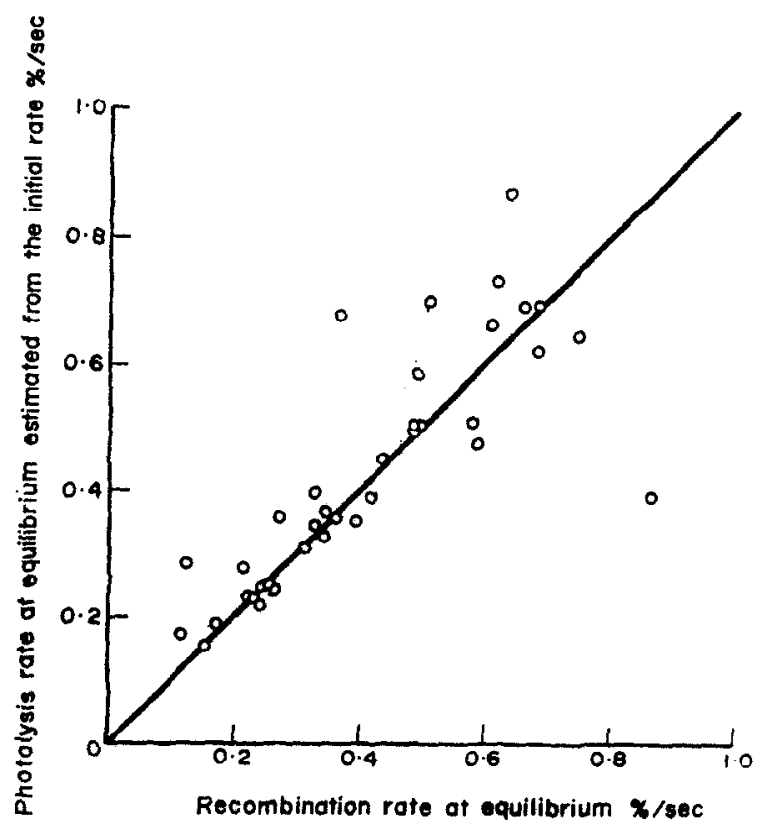

Fko. 3. Photolytin rate at equilibrium estimated from the initial rate in the way shown in Fie. 2a, compared with tho recombination rate at equilibrium entimuted in the way shown in Fig. 2b.

The line shows the theoretical expectation from the peneral kinetic equation.

good agreement with the equilibrium rate of recombination computed from the initial rate of regeneration after the bleaching light was extinguished. This is hardly surprising since the example was selected to illustrate the principle of the test. To what extent is this generally true?

Figure 3 answers this question by illustrating the results of 37 repetitions of this experiment with a variety of bleaching intensities. In this figure the equilibrium rate of photolysis estimated from the initial photolysis rate in the way shown in Fig. $2 \mathrm{a}$ is plotted as a function of the equilibrium rate of recombination computed as in Fig. 2b. If there were perfect agreement, the points would all fall on the solid line drawn in Fig. 3 which has a unit slope and passes through the origin. The agreement is fairly good, in view of the sources of errors already described. We interpret this to exclude the possibility that color products of bleaching, which do not appear in regeneration, mislead application of kinetics described by Equation (3).

B. Loss of the store of 11-cis retinal. Though Fig. 3 is useful in excluding distortions from colored bleached products, it cannot be decided from this plot whether or not changes in the store of 11-cis retinal occurred after different intensities of prolonged bleaching. For that we need to know whether the constants $Q_{\text {. }}$ and $t_{0}$ of Equation (3) are independent of the size of bleach. Figures 4 and 5 answer this question. In Fig. 4 the estimated rate of photolysis at equilibrium as calculated in the way shown in Fig. 2a (open circles) and the rate of recombination at equilibrium as calculated in the way shown in Fig. $2 b$ (black circles) are plotted as a function of the equilibrium amount of unbleached pigment $p$. The results predicted from Equation (3) should fall on a sloping straight line passing through the point $p=1 \cdot 0, d p / d t=0$, with a slope of $1 / t_{0}$. The straight line in Fig. 4 is such a line and 


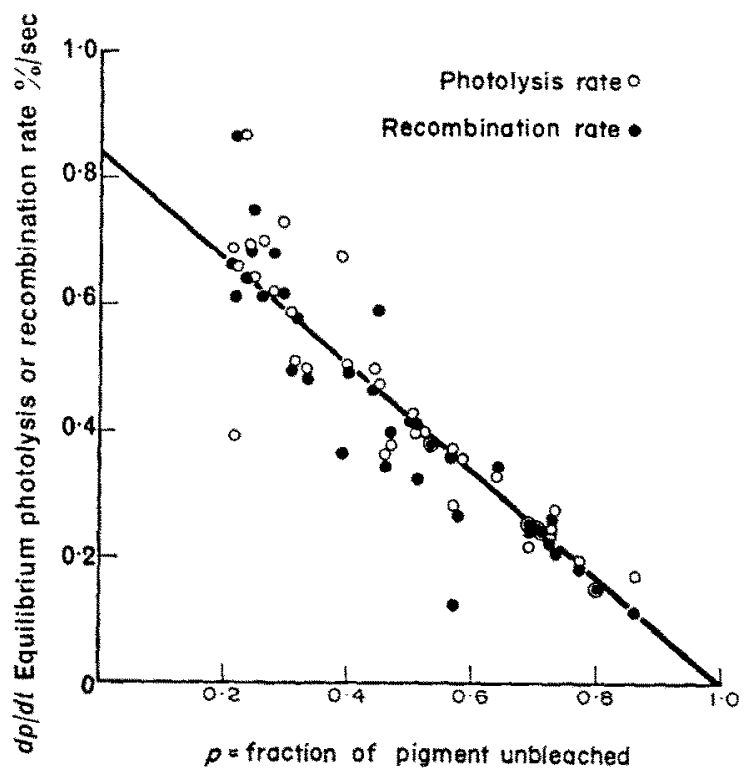

Fig. 4. Estimated photolysis rate (open circles) and recombination rate (Glled circles) at equilibrium plotted as a function of equilibrium fraction of unbleached pigment. The straight line is the theoretical prediction from Equation (3) if $t_{b}=118 \mathrm{sec}$.

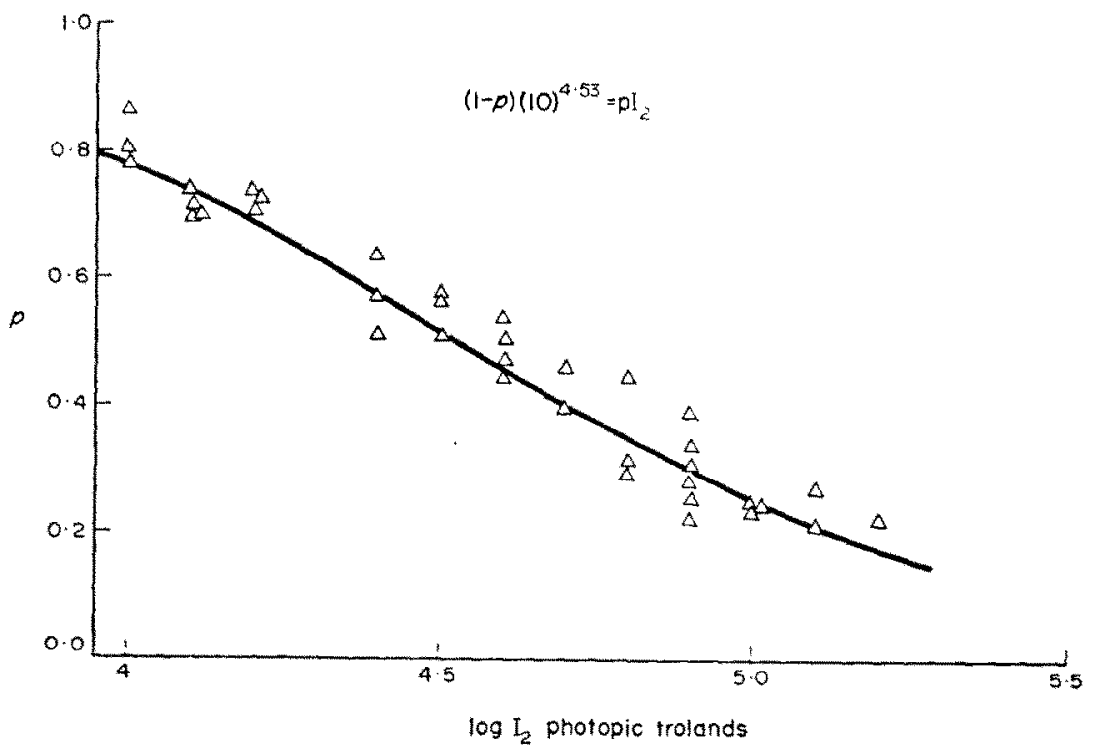

Fig. 5. The equilibrium fractions of unbleached pigment as a function of the bleaching intensity of retinal illuminance (trolands). The smooth curve is theoretical prediction if log $Q_{e} / t_{o}=4 \cdot 53$. 
has a slope such that $t_{0}=118 \mathrm{sec}$. The scatter of points around this line is regarded as reasonable in view of the sources of error and the value for $t_{0}$ is in good agreement with the value of $130 \mathrm{sec}$ for mixed pigment (RuSHTON, 1958), $125 \mathrm{sec}$ for chlorolabe (RushroN, 1963), $130 \mathrm{sec}$ for erythrolabe (RUSHTON, 1965) and $120 \mathrm{sec}$ for mixed pigments (RusHTON and HENRY, 1958). The differences are probably as much due to individual differences as to experimental error.

Another way in which these results illustrate the accuracy of Equation (3) is shown in Fig. 5 where $p$, the fraction of pigment left in equilibrium under steady exposure is plotted against $\log I_{2}$, the bleaching intensity. In equilibrium the net bleaching rate $d p / d t$ is zero; hence Equation (3) becomes

or

$$
I t_{o} / Q_{e}=(1-p) / p
$$

$$
\log I=\log \left(Q_{e} / t_{0}\right)+\log [(1-p) / p] .
$$

The curve of Fig. 5 is this theoretical expectation slid horizontally to give a good fit. When $p=1 / 2, \log I_{2}$ is seen to be 4.53 which from Equation (6) is the value of $\log \left(Q_{e} / t_{0}\right)$. Since $t_{0}$ is $118 \mathrm{sec}$ (Fig. 4), $\log Q_{e}=6.6$ (in $t d \mathrm{sec}$ ). This is in good accord with value of 6.7 found by RUSHTON (1958) and 6.56 and 6.38 using two different methods found by RUSHTON and HENRY (1968).

\section{DISCUSSION}

These results show that after prolonged bleaches of varying intensities the amount of unbleached pigment at equilibrium can always be described by Equation (3). This result would be improbable if the regeneration after a long full bleach required the replenishment of the 11-cis store while the regeneration after a short full bleach did not, according to the suggestion of Rushron and HENRY (1968). For the prolonged weak bleach is unlikely to exhaust the store, and if it did not then regeneration after prolonged weak bleaches should have a shorter time constant than regeneration after prolonged full bleaches. In fact we find that the regeneration time constant $t_{0}$ is independent of the size of the (prolonged) bleach.

Figure 6 illustrates this once more. It shows representative bleaching curves to equilibrium at five different levels and regeneration curves from six (including from prolonged full bleaching - a process which occurs too quickly to measure by this method). The smooth curves drawn through these results are all according to Equation (3) with fixed value for $t_{0}(2 \mathrm{~min})$ and with values for $Q_{e}$ fixed within the range $(6.6 \pm 0.08 \mathrm{log} t d \mathrm{sec})$ that it can be accurately estimated. It is clear that the results for weak bleaches fit the theoretical curves just as well as those for the strong bleaches.

The possibility remains, however, that even the very weakest prolonged bleaches exhausted the 11-cis store. This possibility can be excluded by the result of the following experiment which was suggested to us by Professor W. A. H. Rushton: after full dark adaptation the eye was exposed to a weak light which bleached about 20 per cent of the pigment at equilibrium after $10 \mathrm{~min}$ as shown by the open circles in Fig. 7. We know from the results shown in Fig. 6, and in fact from all the other experiments described in this paper, that if we had after $10 \mathrm{~min}$ of this bleaching allowed the subject to remain in the dark his pigment would regain the fully dark adapted value following an exponential recovery with a time constant of about $2 \mathrm{~min}$. However, we did not immediately submerge him in darkness, but 


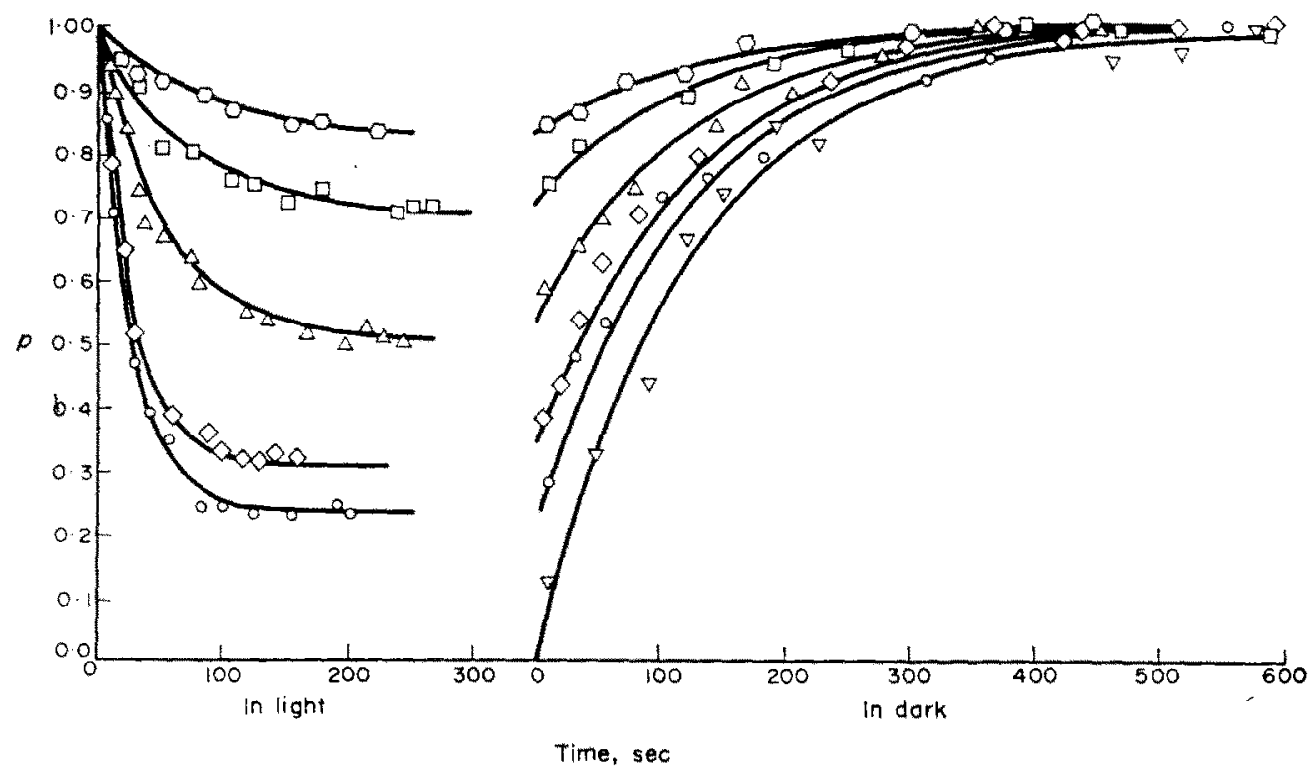

Fig. 6. Representative individual bleaching and regeneration curves. The smooth curves are theoretical according to Equation (3). The values for $\log Q_{e}$ are from above down: $6 \cdot 68,6.62$, $6.64,6.59$ and 6.53 respectively. The value for $t_{0}$ is $2 \mathrm{~min}$ in each case.

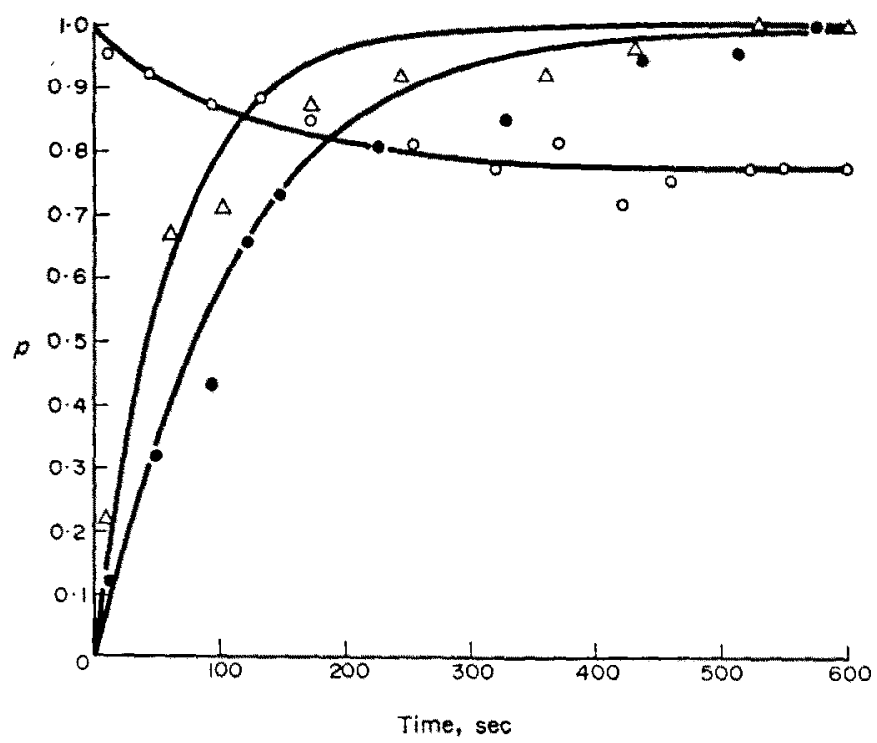

Fig. 7. The triangles show regeneration in the dark following 10 min of weak ( 20 per cent) bleaching (open circles illustrating this partial bleach) followed by full bleach for $5 \mathrm{sec}$. The smooth curve drawn through the triangles has a time constant of $1 \mathrm{~min}$. The solid circles shows regeneration following prolonged full bleach; the smooth curve has a time constant of 2 min. These results are all from a single experimental session. 
first exposed him to a light sufficient to bleach all cone pigment for $5 \mathrm{sec}$ and only then followed regeneration in the dark. If the 10 min 20 per cent bleach had exhausted the 11-cis store, then the regeneration after a $5 \mathrm{sec}$ full bleach should have followed a recovery with a time constant of 2 min such as follows a prolonged full bleach (filled circles Fig. 7). In fact the regeneration after 20 per cent bleach for 10 min followed by a full bleach for $5 \mathrm{sec}$ (triangles, Fig. 7) follows an exponential recovery curve with a time constant of only $1 \mathrm{~min}$ (rather than $2 \mathrm{~min}$ ). The slow recovery from the prolonged weak bleach cannot be attributed to the exhausted 11-cis store, for how then can the quick recovery from the short full bleach which followed the long weak one be explained?

Though our results are clear in showing that the depleted store of 11-cis retinal cannot account for the RUSHTON and HENRY (1968) result we have no alternative explanation for the fact that regeneration after long full bleaches follows an exponential recovery with a time constant of $2 \mathrm{~min}$, but recovery from short full bleaches occurs about twice as fast.

Acknowledgements-Assistod by a grant EY 00197-12 from the National Eye Institute. N. OHan was also asaisted by the WALTER B. PARKRR fund of the University of Michigan. He is on leave from the Department of Ophthalmology, University of Tokyo, Tokyo, Japan. We thank Professor W. A. H. Rushron for suggesting the experiment the results of which are shown in Fig. 7.

\title{
REFERENCES
}

Hood, C. and Rushton, W. A. H. (1971). The Florida retinal densitometer. J. Physiol. (in press).

Rustron, W. A. H. (1958). Kinetics of cone pigments measured objectively on the living human fovea. Ann. N. Y. Acad. Sci. 74, 291-304.

Russtron, W. A. H. (1963). Cone pigment kinetics in the protanope. J. Physiol. 163, 374-388.

Rusurron, W. A. H. (1964). Flash photolysis in human cones. Photochem. Photobiol. 3, 561-577.

Rusurton, W. A. H. (1965). Cone pigment kinetics in the deuteranope. J. Physiol. 176, 38-45.

Rusirton, W. A. H. and HeNRY, G. H. (1968). Bleaching and regeneration of cone pigments in man. Vision Res. 8, 617-631.

\begin{abstract}
Abrtract-Rushton's general kinetic equation for human cone piemeats is tosted by estimating the photolysis rate at equilibrium from the initial photolysis rate and compuring it to the equilibrium rate of regeneration measured immediately after the bleaching lint is turned off. Thirty-seven experiments carried out at a veriety of intermedinto bleaches confirm the validity of this equation. The hypothesis that the regeneration rate depends upon the store of $11-c i s$ retinal leads to the expectation that recovery from a prolonged wenk blewch will proceed with a shorter time constant than recovery from a long intense bleach, and this is not found. This could happen if even the prolonoed weak bleach depleted the 11-eis store but this possibility is excluded by an experiment in which recovery is measured followine 5 sec full bleaching which follows straight on a prolonged weak one. Why recovery from short full bleaches proceed twice as fast as recovery from long full ones remains unexplained.
\end{abstract}

Résumé-On soumet à lépreuve l'équation cinétique générale de Rushton pour les piganents des cônes humains en Evaluant le taux de photolyse à l'Equilibre à partir du taux initial de photolyse et en le comparant au taux d'equilibre de rexincration mesure immidiacement apres extinction de la lumière decolorante. Trente-sept exptriences ralistes diverses decolorations intermédiaires confirment la validité de cette equation. L'hypothése que le taux de rígenération dépend de la provision de rétinal 11-eis fait prévoir que la recuperation apris une faible décoloration prolongte se produira avec une constante de temps plus courte que la récupération apres une decoloration intense, $c$ qui n'a pas lieu. Cela pourrait s'expliquer si la

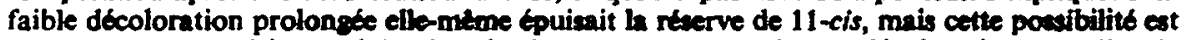
exclue par une expérience ou la rocuptration est meaurte apris une decoloration complette de $5 \mathrm{sec}$ qui suit immediatement une faible dtcoloration prolongte. On ne s'explique pas pourquoi la récuperation aprés de brèves decolorations totales procede deux fois plus vite qu'aprés de longues décolorations totales. 
Zusammenfassung-Rushtons allgemeine kinetische gleichung für die menschlichen Zapfensehstoffe wird geprüft, indem die Geswindigkeit des Photolysengleichgewichtes auf Grund der Anfangsphotolyse geschätzt und mit der sofort nach Auslöschung des Bleichlichtes gemessenen Gleichgewichtsgeswindigkeit der Wiederbildung verglichen wird. Siebenunddreissig Versuche, welche bei verschiedenen Zwischenbleichungen ausgeführt worden waren, bestätigen die Gültigkeit der Gleichung. Die Annahme, dass die Wiederbildungsgeschwindigkeit vom Speicher des 11-cis-Retinals abhänge, führt zur Erwartung, dass die Erholung nach einer langen, schwachen Bleichung schneller vorgehe als die Neubildung nach einer langen, starken Bleichung: dies wird nicht beobachtet. Dies könnte geschehen, falls sogar die lange, schwache Bleichung den 11-cis-Speicher leeren sollte, aber diese Möglichkeit wird durch einen Versuch ausgeschlossen, in welchem die Erholung nach einer 5 Sekunden langen Bleichung, welche einer langen, schwachen Bleichung folgt, gemessen wird. Es ist unerklärt, warum die Erholung nach kurzen Totalbleichungen zweimal so schnall als nach langsamen Totalbleichungen vorgeht.

Резюме - Уравнение общей кинетики колбочковых питментов человека, предложеннсе Rushton подверглось проверке путем определевия скоростей фотолнза при равновесии; брали первоначальную скорость фотолиза и сравнивали ее с равновесной скоростью регенерация, измеренной сразу после выключення отбеливаюшего снета. Тридцать семь экспериментов было вытолнено прк разнообразных промежуточных засветах, которые подтверждают обоснованность этого уравнения. Гипотеза о том, что ход регенерации завксит от 11-cis ретиналя позволяла ожидать, что регенерация в результате иролонгированного отбеливания слабым светом будет происходить с более короткой постоянной времени, чем восстановление в результате длительного интенсивного отбелявания, но этого не найдено. Это могло бы происходить, если бы длительное обесцвечивание слабым светом истодало запасы 11-cis однако, эта возможность исключается экспернментом, где восстановление было измерено после 5 cек. полного обесцвечивания, которое сразу следовало за длительным обесцвечиванитем слабым светом. Почему регенерация питментов после быстрого полного обесцвечивавия провсходит в два раза быстрее, чем восстановление после длительного полного обесивечивавия-остается необъясненньм. 